\title{
O ASPECTO SEMÂNTICO DO PROCESSO E DO PROCEDIMENTO NO DIREITO ADMINISTRATIVO BRASILEIRO
}

\author{
José MarCelo Ferreira COSTA ${ }^{1}$
}

1. Considerações iniciais. 2. O devido processo legal. 2.1. Breves comentários históricos. 2.2. O devido processo legal e a Constituição de 1988. 3. A produção jurídica no Estado Democrático de Direito. 4. Competência para legislar sobre processo e procedimento administrativo. 5. O conteúdo semântico do processo e do procedimento administrativo. 6. As fases do procedimento administrativo. 7. Conclusões. 8. Bibliografia

\section{Considerações iniciais}

O trabalho em apreço propõe-se a abordar o conteúdo semântico dos termos processo e procedimento no direito administrativo, à luz da Constituição Federal de 1988. Desde já, sublinhamos que por razões dogmáticas os enunciados teoréticos aqui lançados têm como objeto formal de estudo o ordenamento jurídico-positivo brasileiro, consoante o referencial espaço-temporal, hic et nunc.

Destacamos que não foram desperdiçados esforços em torno da discussão a respeito dos rótulos. Ao contrário, a missão voltou-se à construção dos signos processo e procedimento na esfera da função administrativa para, ao final, apresentarmos um resultado verdadeiro, consoante a visão proposicional-descritiva da Ciência do Direito. ${ }^{2}$

1 Mestre em Direito de Estado na PUC/SP, Consultor-geral Adjunto do Estado do Rio Grande do Norte, Professor de Direito Administrativo da UnP, da ESMARN e da FESMP/RN.

2 Perante a Ciência do Direito as classificações estão sujeitas apenas aos valores de verdade ou falsidade (terceiro excluído). A Ciência do Direito descreve, a partir dos enunciados prescritivos que compõem o direito posto, o sistema normativo vigente em cada país. Suas proposições apofânticas nomoempíricas descritivas, portanto, submetem-se aos valores bivalentes da lógica alética, verdadeiro ou falso. consoante descortinem correta ou incorretamente o exato sentido das normas 
Como se sabe, o tema ainda é protagonista de controvertidas posições nos palcos da mais autorizada doutrina, tanto perante o cenário nacional como estrangeiro. A não unicidade de resultados hermenêuticos é fruto da diversidade de métodos de análise empregados.

Assim, para o interlocutor melhor compreender nosso propósito, subdividimos o estudo estruturalmente em três partes. Quais sejam:

(i) Primeira Parte: serão tecidas breves considerações a respeito da evolução da garantia do "devido processo legal", originária do direito anglo-saxão, bem como sobre a operacionalização do ingresso da expressão em comento no rol dos direitos fundamentais, da Constituição Federal de 1988.

(ii) Segunda Parte: demonstraremos a preferência do legislador constituinte em reservar o vocábulo processo para designar o fenômeno comum pertinente ao desenvolvimento de todas as funções estatais. Igualmente, bastante influenciados por este momento, discorreremos sobre a competência legislativa dos entes federativos a respeito do tema "processo e procedimento administrativo".

(iii) Terceira Parte: manejaremos recursos semióticos no intuito de afastar os vícios da linguagem e alcançarmos a precisão do discurso científico. $O$ processo será apresentado como relação jurídica indispensável ao desenvolvimento da função administrativa no Estado Democrático de Direito (art. $1^{\circ}$, caput, Lei Magna de 1988). Em seguida, as fases do procedimento serão estudadas de forma individualizada.

Por derradeiro, uma observação: ante a evidente desarmonia presente nas lições doutrinárias consultadas, optamos por relacionar as posições dos mais diversos juristas em notas de rodapé, ao invés de selecionar um item inteiro do trabalho para discorrer a respeito dos seus esforços teórico-científicos.

\section{PRIMEIRA PARTE}

\section{O devido processo legal}

\subsection{Breves comentários históricos}

O "devido processo legal" ${ }^{3}$ brotou no direito inglês no ano de 1215 com a expressão originária de "lei da terra". Na ocasião, elaborou-se uma convenção entre

jurídicas em dado sistema, sem possuir, por assim dizer, pretensão de validade e, encontrando-se, ainda, isento de contradições. Consultar: Lourival Vilanova, As Estruturas Lógicas e o Sistema do Direito Positivo, pp. 191-5.

3 Charles Cole destaca que o conceito do devido processo legal remonta ao princípio hebreu de que justiça requer uma lei justa e compassiva. $O$ autor, após relacionar idéias de filósofos gregos, 
o Rei João Sem Terra e os nobres de alta estirpe para que suas prerrogativas fossem protegidas das eventuais ações abusivas deste (e posterior[es] soberano[s]). Eis que surgiu a Magna Carta, documento que assegurava ao baronato a inviolabilidade à vida, à liberdade e à propriedade, direitos estes passíveis de perda somente de acordo com a "lei da terra" ou consoante o prévio julgamento dos seus pares. ${ }^{4}$

No ano de 1354, durante o reinado de Eduardo III, uma lei do Parlamento inglês substituiu o rótulo "lei da terra" (per legem terrae) por due process of law, por "obra de 'some unknown draftsman' e em virtude de motivos ignorados". ${ }^{5}$ Os séculos se passaram e, naturalmente, com a evolução dos institutos jurídicos e políticos ingleses o conteúdo do due process of law adensou-se, recebendo os primeiros traços de caráter processual, tais como o requisito do notice and hearing (prévia ciência ou citação). Ao depois, a edição da Petition of Rights (1628) impôs que ninguém deveria ser preso sem que houvesse a evidência de uma justa causa. ${ }^{6}$

No século XVII, um caso concreto - The Dr. Bonham's case ${ }^{7}$ - envolvendo a entidade competente para licenciamento do exercício (e aplicação de sanções) da profissão médica, levado ao Tribunal de Common Pleas britânico, foi o grande responsável pelo destino do devido processo legal no insular país europeu. $\mathrm{Na}$ oportunidade, o magistrado, Sir Edward Coke, ao julgar a lide tentou impor o precedente de que a "lei da razão" revela-se através da boca dos juízes, por assim dizer, jura naturae sunt immutabilia, sunt leges legum. Mas, tal manobra, permeada para firmar o ideal de supremacia do órgão judicante sobre o legiferante - em solo inglês - foi fugaz. O magistrado Coke foi afastado pelo Rei Jaime I, o Parlamento inglês reafirmou seu poder na Inglaterra e os juízes foram relegados a meros serventes da Coroa e da legislação. ${ }^{8}$

faz comentários pontuais sobre o ancestral mais próximo do commom law inglês, qual seja, o direito romano e os princípios da equiidade e imparcialidade ("O Devido Processo Legal na Cultura dos Estados Unidos: Passado, Presente e Futuro", in: Revista da AJUFE, p. 34-5).

4 Art. 39, da Magna Carta: "No free man shall be seized or imprisoned, or strippede of his rights or possessions, or outlawed or exiladed, or deprived of his standings in any other way, nor will be proceed with force against him, or send others to do so, except by the lawful judgement of his equals or by the law of the land".

5 Sampaio Dória, Origem e Evolução da Cláusula Due Process of Law, p. 12.

6 lbid, p.14.

7 “Na famosa questão denominada Bonhan's Case, o juristá notável que foi COKE sustentou serem nulos os atos do Parlamento contrários ao Common Law, alegando que eles podiam em certas situações ser contrastados" (in: Oswaldo Aranha Bandeira de Mello, A Teoria das Constituições Rígidas, p. 106).

8 Oswaldo Aranha Bandeira de Mello (A Teoria.... op. cit., p. 112) explica o porquê da resistência européia em reconhecer ao Judiciário o poder de declarar írritas e nulas as leis inconstitucionais. Segundo o autor "a explicação de não ter sido, na Europa, adotada esta doutrina, ao começo, é devido à falta de lógica em se não chegar às últimas consequiências dos princípios aceitos, ocasionada, em grande parte, pela influência de ROUSSEAU, esta redundando em verdadeiro fanatismo pelas assembléias populares”. Já Sampaio Dória (In: op. cit., p. 20) ilustra a onipotência do Parlamento inglês ao citar a seguinte passagem: "Parliament can do anything but make a man a woman". Por sua vez, James Madison Jr. (In: Publius, $\mathrm{n}^{\circ}$ 51) escreveu que, na Inglaterra, o 
Com efeito, a expansão ultramarina dos ingleses fez com que suas riquezas culturais fossem levadas ao Novo Mundo, fazendo com que as Leis Fundamentais instituídas pelas várias colônias, sobretudo as fundadas na América do Norte, herdassem a garantia do devido processo legal. ${ }^{9}$

Após o processo de Independência (1776), sucedido pela frustrada instituição da Confederação, ${ }^{10}$ surgiu a Federação como único instrumento de fortalecimento político e econômico da recém-criada nação norte-americana. A Convenção Nacional da Filadélfia, em 1787, culminou com a edição de um Documento Legislativo Fundamental. Este documento, redigido por conhecedores ávidos das correntes filosóficas iluministas pregadas pelo jusnaturalistas europeus (dos séculos XVI e XVII), foi o marco gerador da transformação em direito positivo de certos ideais políticos lançados à época (por exemplo, a tripartição das funções do Estado, soberania popular etc.).

No corpo do texto principal desta Lei Maior o due process of law não recebeu o merecido tratamento. Somente com a elaboração das "Dez Primeiras Emendas", acordo político rotulado de Bill of Rights, datado de 15 de dezembro de 1791, a garantia obteve o merecido status constitucional. Ressalte-se que, neste primeiro momento, tal como no direito inglês, a cláusula significou somente exigência de um processo regular e ordenado, ou seja, o caráter formal do procedural due process.

Porém, aos poucos, o caminho perfilhado pelo devido processo legal na América do Norte distanciou-se da paradigmática matriz inglesa.

Os norte-americanos, ao contrário das inclinações da metrópole de outrora, repeliram veementemente a onipotência tirânica do Legislativo, buscando o "direito dos tribunais de declararem nulos os atos do Legislativo, por serem contrários à Constituição, resultando-se de supor que a doutrina importaria em superioridade do Judiciário sobre o Legislativo". "Logo, aquelas investidas idealizadas pelo magistrado inglês Lorde Coke, no intuito de derrubar a proeminência do Parlamento britânico, afloraram no solo norte-americano, onde se conferiu ampla hegemonia ao Judiciário para interpretar as leis e a Constituição, fixando-lhes a significação.

$\mathrm{O}$ ingresso do conteúdo substancial do due process of law tem como marco histórico o desfecho da Guerra de Secessão, quando foram editadas as chamadas "emendas de reconstrução" ( $\mathrm{n}^{\circ}$ s XIII, XIV e XV). A Emenda XIII aboliu a escravidão e o trabalho involuntário (em 1865). A Emenda XIV conferiu a igual proteção

Parlamento significava a representatividade popular máxima, revelando as grandes aspirações da sociedade. Ao contrário, na América do Norte havia um evidente preconceito contra o Poder Legislativo. Dois instrumentos impuseram limites aos poderes do ente legislativo estadunidense: i) o controle difuso das leis (judicial review) e ii) o veto presidencial.

9 Carlos Roberto Siqueira Castro destaca que Leis Fundamentais já exibiam a garantia do due process of law sob a fórmula originária law of the land. Para obter uma visão panorâmica das Cartas primitivas das colônias inglesas que antecederam a formação da federação norte-americana consultar: $O$ Devido Processo Legal e a Razoabilidade das Leis na Nova Constituição do Brasil, p. 12 e ss.

10 Cf. Dalmo de Abreu Dallari, Elementos de Teoria Geral do Estado, p. 216.

11 Alexander Hamilton, Publius, $n^{\circ} 78$. 
legal aos cidadãos (1868). A Emenda XV ampliou o direito de voto independentemente da raça, cor, ou condição anterior de escravidão (1870). ${ }^{12}$

Tais Emendas, sobretudo a XIV, ao preverem a equal protection of the law, possibilitou ao Judiciário amplos meios para sindicalizar os atos jurídicos, evitando-se os arbítrios legislativos, ${ }^{13}$ quando irrazoáveis ou irracionais (fase do substantive due process). ${ }^{14}$

Teremos oportunidade de constatar, ao longo do presente trabalho, que o conteúdo da garantia constitucional inicialmente relegada à jurisdição penal, migrou, ao depois, à jurisdição civil, estendendo-se também ao âmbito da Administração Pública. ${ }^{15}$

\subsection{O devido processo legal e a Constituição de 1988}

Toda a análise retrospectiva levada a efeito no item anterior, ainda que perfunctória, fez-se imprescindível à adequada compreensão da cláusula devido processo legal. Como sabemos, encontra-se expresso no elenco dos direitos e garantias fundamentais da Constituição Federal do Brasil de 1988 (art. $5^{\circ}$, inciso LIV) que "ninguém será privado de sua liberdade ou de seus bens sem o devido processo legal".

Reflita-se: apesar de todas as nossas Cartas Republicanas terem traços inspirados no correlativo texto norte-americano, até então, a garantia em apreço não tinha figurado expressamente em nenhum Documento Fundamental do país. ${ }^{16}$ Assim, operacionalizado o ingresso positivo do instituto estadunidense, alguns cotejos são imprescindíveis ao exato delineamento da sua abrangência em nossa aldeia.

Charles Cole ${ }^{17}$ ao se referir à internacionalização da cláusula due process of law, leciona que "qualquer transplante de conceitos constitucionais para aplicação mais ampla internacionalmente dos conceitos judiciais, requer que as pessoas a serem

12 Observe-se que o direito de voto só foi estendido às mulheres com a Emenda XIX, de 26 de agosto de 1920.

13 Ao contrário, como vimos alhures, perante o direito inglês, a hegemonia do Parlamento sempre foi a regra: "Se o Parlamento editar, de forma positiva, uma lei que soe desarrazoada, desconheço qualquer poder, dentro dos cânones tradicionais da Constituição, que disponha de autoridade para invalidá-la" (Sampaio Dória, Origem e Evolução, op. cit., p. 22, nota de rodapé n 37 ).

14 "O abandono da visão estritamente processualista da cogitada garantia constitucional (procedural due process) e o início da fase 'substantiva' na evolução desse instituto (substantive due process) retrata a entrada em cena do Judiciário como árbitro autorizado e final das relações do governo com a sociedade civil, revelando o seu papel de protagonista e igualmente 'substantivo' no seio das instituições governativas" (In: Carlos Roberto de Siqueira Castro, op. cit. p. 57). Já segundo Albrecht Weber (In: El Procedimiento Administrativo en el Derecho Comunitário, p. 86) o "due process, derecho al proceso debido o processo justo, en su formulación originaria angloamericana. En la doctrina alemana, se habla de ein Gebot der Fairne $\beta$, es decir, literalmentre, mandato ou imperativo de practicar um juego limpio".

15 Cf. Odete Medauar, A Processualidade no Direito Administrativo, p. 81.

16 Cf. Antonio Carlos de Araújo Cintra, Ada Pellegrini Grinover e Cândido Dinamarco, Teoria Geral do Processo, p. 82.

17 Op. cit., p. 41. 
servidas por aqueles conceitos tenham valores semelhantes ou compartilhados, se quisermos assegurar uma eficácia semelhante de tais conceitos".

Em outras palavras: acatando os ensinamentos do professor de Direito Constitucional da Universidade de Samford, o sucesso e aplicação da construção anglo-saxônica, ora lançada expressamente no sistema constitucional-positivo brasileiro. ${ }^{18}$ relaciona-se essencialmente com as "condições ambientais" aqui existentes. $\mathrm{E}$, ao que nos parece, a semente do devido processo legal encontrou aqui um solo já preparado para sua germinação e desenvolvimento.

Já nos primeiros anos da segunda metade do século passado, San Tiago Dantas ${ }^{19}$ sustentou, com peculiar clareza, que os mesmos resultados obtidos pela Suprema Corte norte-americana, com a aplicação da cláusula due process of law eram aqui efetivamente obtidos, independentemente de possuímo-la ou não escrita/expressa nos nossos textos legislados.

Segundo o referido autor, a simetria de efeitos entre o direito constitucional brasileiro e o correspondente norte-americano sempre se deu pelas seguintes razões: (i) no Brasil, desde o primeiro estatuto republicano, o mecanismo de controle jurisdicional foi amplamente privilegiado, ou seja, não se acatou a tradição européia de supremacia do Legislativo; e (ii) o acolhimento do princípio da igualdade, ${ }^{20}$ herdado do direito francês, possibilitou ao Judiciário brasileiro examinar substancialmente o conteúdo das produções legislativas.

Logo, em que pesasse à inexistência da expressão "devido processo legal" no ordenamento jurídico brasileiro, graças ao binômio princípio da igualdade/controle jurisdicional, resultados similares ao característico regime estadunidense puderam ser observados em nossa jurisprudência, mesmo antes da Carta de 1988. Portanto, a importação (e introdução) da expressão constitucional para o direito pátrio não ocasionou um regime jurídico inédito ou desconhecido por essas terras meridionais.

Consoante Cármen Lúcia Antunes Rocha ${ }^{21}$ sempre o "constitucionalismo positivo albergou o princípio do devido processo legal (conquanto sem a utilização da expressão)". Assim, a eficácia do conceito da cláusula due process of law, por se tratar de um enérgico mecanismo de controle de legalidade e de razoabilidade dos atos normativos (e da generalidade das decisões estatais) tende, ao nosso ver, ser bastante proveitoso e fecundo em nosso país.

Do avanço das nossas considerações inferimos as seguintes conclusões parciais: (i) o vigente ordenamento constitucional-positivo brasileiro determina que o fenô-

18 "Define-se sistema como um conjunto de elementos (partes) que entram em relação formando um todo unitário" (Marcelo Neves, Teoria da Inconstitucionalidade das Leis, p. 2).

19 Igualdade Perante a Lei e Due Process of Law, pp. 53-4.

20 "Ora, aprofundando o exame do sistema constitucional vigente, podemos ver que o seu centro gerador, o eixo em torno do qual se cristalizam as normas e instituições de direito público, é, precisamente, o conceito de igualdade" (San Tiago Dantas, idem, p. 56).

21 "Princípios Constitucionais do Processo Administrativo no Direito Brasileiro", in: RDA 209/1997. p. 203. 
meno de criação/aplicação ${ }^{22}$ do direito, envolvendo os bens jurídicos da liberdade e da propriedade, seja realizado mediante a observância do processo em sua acepção adjetiva e substantiva $;^{23}$ e (ii) o desenvolvimento das funções estatais (administrativa, legislativa e jurisdicional) deve ser permeado pelo respeito à garantia constitucional do devido processo legal.

Adiante, o estudo segue canalizando maior ênfase no âmbito da função administrativa, sem deixar de lado certas referências às demais funções estatais, pois, conforme o inicialmente proposto, faz-se necessária a redução do objeto de análise a um território mais específico, por razões epistemológicas.

\section{SEGUNDA PARTE}

\section{A produção jurídica no Estado Democrático de Direito}

Com o advento da Constituição Federal de 1988, o processo administrativo ganhou nova feição no cenário brasileiro. A inequívoca jovialidade do tema não é privilégio exclusivo do nosso país, haja vista a dogmática no direito comparado só ter despertado seu interesse sobre o assunto há pouco mais de 100 anos. $^{24}$

Com efeito, a tendência da doutrina nacional sempre se voltou à circunscrição do rótulo processo na esfera da função jurisdicional. Mas, como restará demonstrado, consoante a inteligência de várias passagens do vigente texto redigido pelo legislador constituinte, o processo encontra-se umbilicalmente ligado ao pleno desenvolvimento de todas as funções estatais. Aliás, a atual ótica constitucional nos leva a crer que

22 Segundo Hans Kelsen, "a criação do direito é sempre a aplicação do direito (...). Que a criação do Direito seja, ao mesmo tempo, aplicação do Direito é uma consequiência imediata de que todo ato criador de Direito deve ser determinado pela ordem jurídica". Entretanto, há dois casos ressalvados pelo próprio autor, quais sejam: a) os atos pelos quais não se estabelece nenhuma norma (mera aplicação do direito), é o caso da sanção num caso concreto; e b) a norma fundamental, que determina a criação da primeira Constituição, vez que sendo pressuposta pelo pensamento jurídico, a sua pressuposição não é, ela própria, determinada por nenhuma norma superior e, portanto, não é aplicação de Direito" (Teoria Geral do Estado e do Direito. pp. 193-4).

$23 \mathrm{O}$ devido processo legal concerne tanto à forma quanto ao conteúdo das decisões. Por ele se garante a certeza do dever público quanto ao direito do particular na relação jurídica. No sentido substancial liga-se à estreita adequação escalonada entre as normas superiores que delimitam o conteúdo de formação das normas inferiores. No aspecto adjetivo, diz respeito à observância do procedimento específico a ser obedecido, na ótica formal, para a correta criação/aplicação do direito. 24 “(...) nell'area latino-germanica e quali manifestazioni perspicue dello Staatrecht alla Verwal. tungsvereinfachugsgesetz autriaca (1925), che, sulla scorta della legge constitutiva del supremo tribunale amministrativo, del 1875, e dell'opera del Tezner (1896) detta regole uniformi sul procedimento amministrativo (peraltro, la prima legge generale sulla procedura amministrativa è quella spagnola del 1875" (Elio Fazzalari, op. cit., p. 820). Cf. Odete Medauar, op. cit., p. 139. 
o processo vincula-se a uma relação jurídica de direito público, peculiar à atuação deste Estado que se diz Democrático e de Direito. ${ }^{25}$

Sobre o asunto, as observações de Carlos Ari Sundfeld ${ }^{26}$ merecem ser transcritas na íntegra:

“As várias funções do Estado - pouco importa como as classifiquemos resultam na produção de normas jurídicas. $\mathrm{Na}$ legislativa se produzem as leis e na administrativa e judiciária são elas executadas, através da produção de novas normas jurídicas (atos administrativos ou judiciais). Na produção de cada um destes atos, que se encadeiam hierarquicamente em pirâmide, o agente estatal deve estar atento ao conteúdo da norma superior, para a ela adequar o seu ato. Este já é um meio importante de controle do exercício da autoridade, que garante que os atos estatais guardem entre si coerência, de acordo com padrões sucessivamente estabelecidos (na Constituição, nas leis, nos decretos, etc.)".

Em outro trabalho, da lavra do mesmo autor, ${ }^{27}$ extraímos o seguinte trecho:

"No Estado Democrático de Direito, o exercício das diferentes funções estatais - e. em consequiência, a produção dos atos de direito público exige a observância de processo perfeitamente regulado pelas normas jurídicas."

"Constatamos, de conseguinte, que o processo é o modo normal de agir do Estado."

Seguindo a trilha traçada pelo jurista paulistano, sustentamos que entre o veículo introdutor de norma jurídica de hierarquia superior (uma lei ordinária, por exemplo) e o exatamente inferior (um ato administrativo, por exemplo), não há passes automáticos, mas sim comandos deonticamente modalizados que precisam ser observados para a regular aplicação/criação do direito posto. Deste modo, em regra, a atuação estatal precisa vestir a roupagem de uma relação jurídica processual para tornar possível a escalonada concretização do direito perante as funções administrativa, legislativa ou jurisdicional.

Em verdade, ao corrermos os olhos na atual Lei Fundamental, notamos que o legislador faz amplo uso do vocábulo processo para evidenciar o fenômeno característico da formação das mais diversas atividades do Estado. ${ }^{28}$

25 Cf. Albrecht Weber, El Procedimiento Administrativo..., op. cit., p. 75 e ss.

26 “A Importância do Procedimento Administrativo", in: RDP 84/1987, p. 72.

27 Carlos Ari Sundfeld, Fundamentos de Direito Público, p. 90.

28 "Processo é conceito que transcende ao direito processual. Sendo instrumento para o legítimo exercício do poder, ele está presente em todas as atividades estatais (processo administrativo, legislativo) e mesmo não-estatais (processos disciplinares dos partidos políticos ou associações, 
Abaixo relacionamos alguns exemplos de dispositivos constitucionais, afora os relativos às funções jurisdicional e legislativa, que nos permitem evidenciar a preferência semântica do constituinte de 1988:29

Art. $5^{\circ}$ - omissis:

LIII - ninguém será processado nem sentenciado senão pela autoridade competente;

LIV — ninguém será privado da liberdade ou de seus bens sem o devido processo legal;

LV — aos litigantes, em processo judicial ou administrativo, e aos acusados em geral são assegurados o contraditório e ampla defesa, com todos os meios e recursos a ela inerentes.

LVI — são inadmissíveis, no processo, as provas obtidas por meios ilícitos; LXXIII - conceder-se-á habeas data:

b) para a retificação de dados, quando não se prefira fazê-lo por processo sigiloso, judicial ou administrativo.

Art. 16 - A lei que alterar o processo eleitoral entrará em vigor na data de sua publicação, não se aplicando à eleição que ocorra até 1 (um) ano da data de sua vigência.

Art. 37 - omissis:

XXI - ressalvados os casos específicos na legislação, as obras, serviços, compras e alienações serão contratadas mediante processo de licitação pública que assegure a igualdade de condições a todos os concorrentes, com cláusulas que estabeleçam obrigações de pagamento, mantidas as condições efetivas da proposta, nos termos da lei, a qual somente permitirá as exigências de qualificação técnica e econômica indispensáveis à garantia do cumprimento das obrigações.

Art. 41 - O servidor público estável somente perderá o cargo:

II - mediante processo administrativo que lhe seja assegurada ampla defesa;

Art. 247 - Omissis;

Parágrafo único: Na hipótese de insuficiência de desempenho, a perda do cargo somente ocorrerá mediante processo administrativo em que lhe sejam assegurados o contraditório e a ampla defesa.

processos das sociedades mercantis para aumento de capital, etc.)" (Antonio Carlos de Araújo Cintra, Ada Pellegrini Grinover $e$ Cândido Dinamarco, Teoria Geral..., op. cit., p. 276).

29 Não há grifos no texto original. 
Desde o primeiro documento da República do Brasil (1891), o federalismo foi acolhido como princípio basilar à estruturação do Estado, ${ }^{30}$ consubstanciando-se em verdadeiro exemplo de decisão política fundamental, no sentido de Carl Schmitt.

A presente Constituição reservou à descentralização política tratamento especial, conferindo-lhe o caráter de cláusula pétrea, ou seja, imutável perante o chamado Poder Constituinte Derivado (Poder de Reforma), face o disposto no art. 60, $\S 4^{\circ}$, inciso I, que diz: "não será objeto de deliberação a proposta de emenda tendente a abolir a forma federativa de Estado".31

Outrossim, a Lei Magna de 1988 ocupou-se em definir os entes federativos e traçar-lhes certos contornos, ${ }^{32}$ exempli gratia, a auto-organização político-administrativa $^{33}$ (art. 18, caput). Resta-nos perquirir quais as características essenciais da federação, sobretudo no que tange à autonomia, atributo maior dos entes federativos e ponto basilar da investigação a respeito da competência constitucional para legislar sobre processo e procedimento administrativo.

A propósito dos temas federação e autonomia, é preciso transcrever as insuperáveis observações do jurista germânico Jellinek, ${ }^{34}$ quando com muita propriedade versou: "o Estado Federal é soberano, perfeito e completo, mas o Estado-membro não o é, porém não deixa de ser Estado, pois é dotado de uma 'autonomia constitucional', distinguindo-se por esse atributo das demais coletividades inferiores".

Ora, é insofismável que quem diz federação diz a existência de mais de um núcleo de poder autônomo, e, por ilação lógica, tal autonomia significa autogoverno, auto-organização ou, ainda, autorregulação ${ }^{35}$ no âmbito de cada ente federativo. Porquanto, da mesma raiz que brota a competência para a emanação dos atos

30 "O Estado Federal é um fenômeno moderno, que só aparece no século XVIII, não tendo sido conhecido na Antiguiidade e na Idade Média". Mais adiante: "O Estado Federal nasceu, realmente com a Constituição dos Estados Unidos da América, em 1787" (Dalmo de Abreu Dallari, Elementos de Teoria Geral do Estado, p. 216).

31 Diferenciando-se da forma de governo republicano, que surgiu na pele dos chamados princípios sensíveis da Constituição (art. 34, inciso VII, alínea a). Art. $2^{\circ}$, caput, do ADCT: "No dia 7 de setembro de 1993 o eleitorado definirá, através do plebiscito, a forma (república ou monarquia constitucional) e o sistema de governo (parlamentarismo ou presidencialismo) que devem vigorar no país."

32 Cf. arts. 18 usque 36, da Constituição Federal de 1988.

33 “Art. 18 - A organização político-administrativa da República Federativa do Brasil compreende a União, os Estados, o Distrito Federal e os Municípios, todos autônomos, nos termos desta Constituição".

34 Apud Pinto Ferreira, Princípios Gerais do Direito Constitucional Moderno, p. 739. O pensamento de Jellinek mereceu os seguintes comentários de Pinto Ferreira: "é uma das mais formosas e sólidas construções do direito público, ou uma explicação bem escorreita da federação, numa superação espiritual profunda sobre as doutrinas precedentes, servindo de base a uma indagação mais apurada, bem ajustada à realidade social e jurídica, a permitir uma compreensão objetiva e científica do federalismo".

35 Cf. J. H. Meirelles Teixeira, Curso de Direito Constitucional, p. 647. 
administrativos, em cada compartimento político autônomo, real fonte instauradora das relações intersubjetivas entre o Poder Público e o(s) administrado(s), nasce a atribuição ao respectivo ente para legislar sobre o processo e o procedimento referente ao modo como mencionada relação jurídica deva ser confeccionada.

Cármen Lúcia Antunes Rocha ${ }^{36}$ posiciona-se sobre a temática de maneira clara e precisa: "se o processo administrativo, instrumentalizador das condutas administrativas e somente utilizado para a garantia dos direitos subjetivos do cidadão e do administrado em geral, não fosse inserido no espaço de competência própria e autônoma de cada entidade federada, como se ter que a auto-administração dessa pessoa estaria garantida? Como dizer autônoma para organizar a sua própria administração quem não dispõe de autonomia política para legislar, sequer sobre o processo a ser seguido no exercício dessa matéria?"

É de se concluir que cada ente porta competência para legislar a respeito do processo no âmbito da sua esfera político-administrativa. À guisa de exemplificação, podemos relacionar três diplomas legais que surgiram em nosso ordenamento pátrio tratando da matéria: (i) a Lei do Estado de Sergipe (Lei Complementar Estadual $n^{\circ}$ 33/96); (ii) a Lei do Estado de São Paulo ( $\left.\mathrm{n}^{\circ} 10.177 / 98\right)$; e (iii) a Lei Federal $\left(\mathrm{n}^{\circ}\right.$ 9.784/99).

Sem embargo, resta-nos ainda um aspecto a ser enfrentado. Alguns dispositivos constitucionais são merecedores de acurada análise no sentido de evitar distorções hermenêuticas a respeito do tema processo e procedimento administrativo.

$\mathrm{O}$ art. 22, da Constituição Federal, diz que a União detém competência privativa para legislar sobre "direito civil, comercial, penal, processual, eleitoral, agrário, marítimo, aeronáutico, espacial e do trabalho". De primeira leitura, poder-se-ia pensar que somente a União (ressalvada a especial hipótese do parágrafo único do citado artigo) teria competência para legislar sobre processo administrativo.

A isolada interpretação exegética deve ser afastada, pois seria o mesmo que sustentar a atribuição da União para editar a legislação nacional ${ }^{37}$ sobre o processo administrativo. Contudo, certamente não foi esta a opção do legislador constituinte.

Assome-se que, se provável jurista pretender descrever o fenômeno processual de maneira tão inadequada, no âmbito da função administrativa, estaria admitindo uma nítida invasão, por parte da União Federal, na esfera de autonomia dos demais entes políticos, posição esta totalmente embriagada de vícios quanto à sua constitucionalidade. $^{38}$

36 Op. cit., p. 198.

37 Geraldo Ataliba diferencia lei nacional de lei federal. A Lei Federal vincula todo o aparelho administrativo da União e todas as pessoas que a ele estejam subordinadas ou relacionadas, em grau de sujeição, na qualidade de seus administrados e jurisdicionados, sem acolher os Estados, Municípios, Distrito Federal, e suas autarquias. Já a Lei Nacional é categoria jurídico-positiva mais ampla e transcende as distinções estabelecidas em razão das circunstâncias políticas e administrativas, consubstanciando-se em um produto legislativo global ("Normas Gerais de Direito Financeiro", in: RDP 10, pp. 49-55).

38 Dessa feita, acertou o legislador federal ao estabelecer no art. $1^{\circ}$, da Lei $n^{\circ} 9.784 / 99$, sua abrangência restrita à Administração Federal direta e indireta editar uma lei que vincula lei nacional 
Em suma, quando o legislador constituinte conferiu competência privativa à União para legislar em matéria processual (art. 22, inciso I) estava referindo-se ao direito processual civil e penal (incluindo-se a jurisdição especial trabalhista e eleitoral).

A mesma linha de entendimento deve ser acolhida quanto ao enunciado do inciso XI, do art. 24, da Lei Fundamental, que reza a competência concorrente da União, Estados e Distrito Federal para legislar sobre "procedimentos em matéria processual". Tal competência serve apenas para facultar aos Estados-membros a viabilização de certos ajustes a propósito da organização do movimento forense.

Aqui nos servem de calço os destaques apostilados por Vicente Greco Filho ${ }^{39}$ : "É competência concorrente da União e dos Estados legislar sobre procedimentos em matéria processual (art. 24, XI), devendo entender-se 'procedimentos em matéria processual' os procedimentos administrativos de apoio ao processo e não o procedimento, que é indissociável do direito processual". Ainda o mesmo autor: "Ao Estado compete legislar sobre Organização Judiciária, definindo as circunscrições de atuação dos juízos, a distribuição da competência entre eles, quando houver mais de um em cada foro, o quadro judiciário e a carreira da magistratura estadual."

Considerando o processo administrativo o instrumento segundo o qual a Administração Pública de cada ente federativo alcança suas ações de forma autônoma, é incontroverso que cada pessoa política detém competência para editar sua própria legislação pertinente, tão-somente limitada pelas disposições lançadas na Constituição Federal de 1988, sobretudo no que tange aos seus princípios.

\section{TERCEIRA PARTE}

\section{5. $O$ conteúdo semântico do processo e do procedimento administrativo}

A expressão processo administrativo é polissêmica, portanto usada, ${ }^{40}$ segundo lições da mais profícua doutrina em várias acepções, denotando indistintamente o seguinte: (i) conjunto de papéis e documentos, isto é, suporte material (os autos); (ii) sinönimo de processo disciplinar; (iii) sinônimo de procedimento administrativo; (iv) sequiência de atos coordenados destinados à solução de controvérsias (presença do contraditório); e (v) conjunto de atos direcionados à obtenção de uma decisão final em sede administrativa.

É incontroverso que a locução processo administrativo, perante a linguagem técnica, sirva às diversas significações ora relacionadas. ${ }^{41}$ Mas, em se tratando de

sobre o tema. No mesmo sentido é o art. $1^{\circ}$, da Lei 10.177/98 (Lei de Processo Administrativo do Estado de São Paulo).

39 Direito Processual Brasileiro, p. 70.

40 Aprofundar a distinção entre "uso" e "menção" em: Wisley Salmon, Lógica, p. 73.

41 "Las palavras no son más que rótulos de las cosas: posemos rótulos a las cosas para hablar de ellas, y por onde las palavras no tienen más relacion com las cosas, que la que tiene los rótulos 
uma investigação científica, a unicidade dos termos, bem como a precisão da linguagem em relação ao objeto tratado e aos seus diversos campos de aplicação, clama pela purificação do discurso. ${ }^{42}$

Um efêmero contato com os estudos desenvolvidos sobre o tema, presentes no Brasil ou em outros países, ${ }^{43}$ é suficiente para desvelar a diversidade de interpretações. A discordância é gerada em razão de variada gama de critérios adotados. ${ }^{44}$

Há autores que firmam o vocábulo processo referindo-se indistintamente às funções administrativa, jurisdicional e legislativa, posto se tratar de um instrumento de realização do direito público. No que tange ao procedimento, este significa o conjunto de formalidades a serem observadas para a prática dos atos jurídicos. ${ }^{45}$

Já outros filiam-se à corrente que propõe a utilização da expressão procedimento administrativo ao invés de processo administrativo. Os que perfilham tal tese entendem que a palavra processo liga-se ao exercício da função jurisdicional, onde o regime jurídico-processual já se encontra delineado (coisa julgada, partes litigando em pé de igualdade, etc.). ${ }^{46}$ Logo, para atuação na esfera administrativa a expressão mais adequada seria "procedimento administrativo". ${ }^{47}$

Outrossim, há os defensores da diferenciação entre processo e procedimento segundo o critério da existência de uma lide ou de acusados. Processo é somente o disciplinar, revisivo ou sancionador, enquanto que o procedimento figura como a forma específica de se desenvolver a função administrativa (bem como das demais funções estatais). ${ }^{48}$

Também merecedora de anotação é a doutrina que relaciona o processo como espécie do procedimento, dispondo que o requisito essencial daquele é a participação

de las botellas com las botellas mismas. Cualquier rótulo es conveniente, en la medida en que nos pongamos de acuerdo acerca de él y lousemos de manera consecuente" (Jonh Hospers apud Agustín Gordillo, Tratado de Derecho Administrativo, Tomo 2, pp. I-12).

42 "La claridad del concepto que se estipule es un prerrequisito de la claridad de todo lo que luego se exponga sobre o tema" (A. Gordillo, op. cit., pp. IX-18).

43 Consultar: Lúcia Valle Figueiredo, Curso..., op. cit., p. 402; Odete Medauar, op. cit., p. 18 e ss. 44 Cf. Marcelo Harger, Principios Constitucionais de Direito Administrativo, pp. 60-1.

45 Maria Sylvia Zanella de Pietro, Direito Administrativo, p. 423 e ss.; Cássio Scarpinella Bueno, Recursos nas Leis de Processo Administrativo (orgs. Carlos Ari Sundfeld e Guillermo Andrés Muñoz, pp. 187-193; Marcelo Harger, Princípios Constitucionais do Processo Administrativo, p. 63.

46 Consultar: Carlos Ari Sundfeld, “A Importância”, op. cit., pp. 69-73; Juan Carlos Cassagne, El Procedimiento Administrativo, pp. 307-310; Agustín Gordillo, Tratado..., op. cit., Tomo 2, pp. IX-6 e ss;.

47 Marcelo Harger (Princípios..., op. cit., pp. 57-8) refuta o uso da expressão "procedimento administrativo". Segundo o autor, tal opção pode causar maiores problemas, pois a "palavra procedimento, via de regra, tem conotação mais fraca que processo". E segue: "Essa "carga mais fraca' que possui o termo 'procedimento' pode acarretar a negação da aplicação de diversos princípios processuais para a realidade processual ocorrida no âmbito administrativo".

48 Consultar: Hely Lopes Meirelles, Direito Administrativo Brasileiro, pp. 586-7; Lúcia Valle Figueiredo, Curso de Direito Administrativo, pp. 402-7; Carmen Lúcia Antunes Rocha, op. cit., p. 190. 
do indivíduo na formação do provimento final, proporcionando a transparência da atividade do órgão e conferindo um instrumento apto à prevenção de lesões injustas, em razão do contraditório. ${ }^{49}$

Após a breve abordagem panorâmica a respeito da temática em apreço, passamos a expor nossa visão teórica. ${ }^{50}$

Ao início, somente será possível identificarmos verdadeiramente a exatidão semântica do signo processo, e o seu correspondente conteúdo jurídico, se olharmos para o tratamento conferido pelo direito positivo brasileiro. Qualquer outra proposição carecerá de valor científico, uma vez que não se descreverá de maneira precisa a realidade vigente, hic et nunc. ${ }^{51}$

Portanto, a corrente defensora do rótulo processo como instrumento ligado exclusivamente à função jurisdicional, sem observância de qualquer construção juspositiva que lhe confira embasamento, reflete uma proposição totalmente refutável por ser insuscetível de demonstração empírica. Pertinente é a observação de Romeu Felipe Barcelar Filho, ${ }^{52}$ ao frisar que "antes de ser jurisdicional ou administrativo, civil ou administrativo, o processo é processo com a identidade que a Constituição lhe fornece".

Não nos resta dúvida que a função jurisdicional é detentora de um regime próprio e consolidado, onde o Estado soluciona de maneira imparcial a controvérsia entre as partes e aplica o direito ao caso concreto de modo definitivo. ${ }^{53} \mathrm{Ou}$, se preferir, conforme os preclaros ensinamentos do memorável Oswaldo Aranha Bandeira de Mello, ${ }^{54}$ a decisão judicial produz um título que "traz a consequêencia da força jurídica consistente no estabelecimento da coisa julgada".

49 "Fra le varie specie di procedimento fa spicci quella indicata come 'processo': quivi la sequenza è disposta in modo che all'iter di formazione dell'atto partecipino, oltre al suo autore, coloro nella cui sfera, l'atto finale è destinato a svolgere i suoi effeti (Questa partecipazione rappresenta un connotato necessario del processo, anche se non ne esaurisce il profilo: si vedrà più innanzi che la nozione di processo è individuata non dall'na ma dal come di talle partecipazzione)". (Elio Fazzalari, Procedimento e Processo [Teoria Generale], p. 819-20).

50 "Quem se propuser à formulação de hipóteses científicas ousadas, abertas ao falseamento, deve aprender a conviver com o erro. Quanto mais ousada a teoria, maior a possibilidade de insinuação do erro. Mas em contrapartida maior será o progresso científico se esse erro for rapidamente identificado" (José Souto Maior Borges, Ciência Feliz, p. 21).

5ı Ao analisar a função administrativa na França, sob-ponto de vista da Ciência do Direito, Francis Paul-Bénoit relaciona três regras a serem observadas. A terceira regra dispõe sobre a necessidade de estar verificando constantemente a evolução das realidades jurídicas de cada país, pois, segundo o autor, qualquer noçāo científica somente evidencia a realidade de um dado momento. E segue: "L'analyse scientifique correcte des fonctions ne peut done jamais conduire à des formulations de valeur absolute. Les réalités du droit positif évoluant, une définition correcte des fonctions doit constamment traduire cette évolution" (Le Droit Administratif Français, p. 42).

52 Princípios Constitucionais do Processo Administrativo Disciplinar, p. 54. Um pouco adiante, na página seguinte (p. 55), o autor destaca: "nem o procedimento é sinônimo de função administrativa, nem o processo, de função jurisdicional".

53 Constituição Federal art. $5^{\circ}$, incisos XXXV e XXXVI.

54 Princípios Gerais de Direito Administrativo, p. 23. 
Todavia, daí a supor que o regime inerente à função jurisdicional acarrete igualmente a exclusividade de uso do rótulo processo, em detrimento das demais funções, consubstancia uma proposição errônea e despida de qualquer fundamentação, se recorrermos à ordem jurídica vigente. Além do mais, caso a palavra processo fosse privilégio único pertencente ao desenvolvimento da função jurisdicional, como explicaríamos o processo legislativo ${ }^{55}$ e o processo administrativo, ambos referidos pela Constituição em suas passagens?

Ratifiquemos: o processo perante a ordem instaurada em 1988 é intrínseco ao atuar estatal, no desenvolver de todas as suas funções públicas. Não há porque temer o uso de processo na seara administrativa ou legislativa, por pensar que se poderia criar confusões com o processo jurisdicional. ${ }^{56}$ Consoante Odete Medauar, ${ }^{57}$ é preciso ter a consciência da "processualidade ampla", ou seja, "uma processualidade associada ao exercício de qualquer poder estatal".

Igualmente equivocada é a doutrina que não reconhece o processo na seara administrativa, em face da suposta desigualdade entre as partes, uma vez que a Administração - a um só tempo — figura na relação processual e profere a decisão final. ${ }^{58}$

Para enfrentarmos tal teoria, prima facie, é imprescindível refletirmos a respeito dos nódulos de interseção existentes entre a relação processual e as funções públicas, os quais, no nosso singelo entender, são os seguintes: (i) o processo diz respeito à

55 Art. 59 - O processo legislativo compreende a elaboração de:

I - emendas à Constituição;

II - leis complementares;

III - leis ordinárias;

IV - leis delegadas;

$\mathrm{V}$ - medidas provisórias;

VI - decretos legislativos;

VII - resoluções.

Não há dúvida que a edição da medida provisória é provimento unilateral e se exaure em único ato. Logo, as premissas ora desenvolvidas no presente estudo encontrar-se-iam refutáveis? Não nos parece correta tal assertiva.

Como veremos adiante, há casos extraordinários onde a aplicação/criação do direito se exaure em único ato, sem que sequer se possibilite ao interessado (que irá suportar os efeitos da decisão) a regular participação.

Ademais, afora o peculiar regime jurídico da medida provisória, a lição do constitucionalista José Afonso da Silva (Curso de Direito Constitucional, p. 458) é efusiva: "As medidas provisórias não constavam da enumeração do art. 59, como objeto do processo legislativo, e não tinham mesmo que constar, porque sua formação não se dá por processo legislativo. São simplesmente editadas pelo Presidente da República. A redação final da Constituição não as trazia nessa enumeração. Um gênio qualquer, de mau gosto e ignorante, e abusado, introduziu-as aí, indevidamente, entre a aprovação do texto final (portanto depois de 22.9.88) e a promulgação-publicação da Constituição no dia 5.10.88".

56 Cf. Romeu Felipe Barcelar Filho, Princípios..., op. cit., pp. 50-1.

57 Op. cit., p. 41.

58 Neste sentido: Eduardo Garcia de Enterría e Tomás-Ramón Fernández, Curso de Derecho Administrativo, p. 405. 
positivação escalonada do direito; e (ii) a necessária participação dos interessados da elaboração da decisão final (ainda que através de seus representantes, ${ }^{59}$ tal como no processo legislativo).

Ao depois, a solução para o controvertido ponto levantado pela doutrina requer atenção especial ao modus operandi de cada função estatal (administrativa, legislativa e jurisdicional), ponderando-se isoladamente suas íntimas peculiaridades e regime jurídico selecionado pelo próprio sistema jurídico.

Cremos que o caminho a ser acolhido é viável, caso acatemos os refinados ensinamentos de Renato Alessi. ${ }^{60}$

O doutrinador italiano leciona que a posição do Estado, sob o ponto de vista jurídico, é distinto conforme a função a ser desempenhada ante a relação instituída. Assim, na função legislativa, ao se produzir, em regra, comandos abstratos e gerais, o Poder Público permanece por cima das relações jurídicas e à margem destas. No exercício da função jurisdicional, o Estado-juiz, ao impor a norma aos casos controvertidos, permanece igualmente por cima e à margem da relação jurídica. Por fim, em se tratando da função administrativa, que funciona como instrumento de concreção, a Administração põe-se como parte da relação jurídica, mas conservando a sua superioridade sobre o particular.

Logo, como a Administração Pública tem o dever de aplicar as normas aos casos concretos, quando do gerenciamento da coisa pública, o(s) particular(es) que será(ão) diretamente afetado(s) pelos efeitos irradiados dos seus atos administrativos, deve(m) integrar a relação processual de elaboração do provimento. Entretanto, é importante lembrar que esta participação distingue-se completamente daquela ocorrida no seio da função jurisdicional ${ }^{61}$ ou legislativa, pois os regimes aplicáveis a tais funções são incomparáveis (e incompatíveis), diante da típica posição sobranceira que a Administração Pública conserva para a produção da decisão final.

Também pedimos vênia para refutar a linha de entendimento que postula o pressuposto necessário de controvérsias ou acusações em geral, para que se possa vislumbrar o processo no âmbito da Administração Pública.

A improcedência desta tese é revelada em razão da Constituição referir-se ao processo como uma forma de atuação estatal, e não somente nos casos onde se perfilha a lide. Usemos um pouco de retórica para melhor argumentar nossa posição.

Em um dado manejo de licitação para aquisição de bens, onde 'os concorrentes simplesmente não se confrontam ou apresentam recursos, o caminho para a concretização das disposições legais seguirá sem que nenhuma dissensão tenha aflorado no seu regular curso. Porém, neste caso, despido de qualquer dialética, não teremos

59 Cf. Peter Häberle, Hermenêutica Constitucional, pp. 38-9.

60 Renato Alessi, Sistema Instituzionale del Diritto Amministrativo, pp. 3-4.

61 Quando a Administração está em juízo (no pólo ativo ou passivo de uma ação judicial), ela se põe em igualdade com a outra parte, ainda que conserve certas prerrogativas legalmente previstas. A respeito das prerrogativas do Poder Público consultar as conferências de José Roberto de Moraes e Regina Helena Costa, bem como os seus debates, todos transcritos na obra Direito Processual Público: A Fazenda Pública em Juízo, pp. 66-98. 
como negar a existência de um processo administrativo desenvolvido para aplicação dos dispositivos da Lei $n^{\circ}$ 8.666/93 (e suas posteriores alterações).

Mas, se porventura após a deflagração do edital/apreciação das propostas um disputante insatisfeito com o resultado promove um recurso administrativo, não há que se falar em conversão do então procedimento administrativo (sem controvérsia) em processo administrativo (agora com controvérsia). Ou mais grave, se a referida lide é solucionada pela autoridade superior, cujo efeito é o saneamento da controvérsia, ter-se-á restaurado o procedimento? É dizer: o procedimento inicial vira processo e reverte-se, ao depois, em procedimento administrativo?

Ao que nos parece, a falha de interpretação surge face a equivocada leitura do art. $5^{\circ}$, inciso LIV, da Lei Máxima, que reza: "aos litigantes, em processo judicial ou administrativo, e aos acusados em geral são assegurados o contraditório e a ampla defesa, com os meios e recursos a ela inerentes".

O dispositivo em comento privilegia o modal deôntico obrigatório, na medida em que consagra a ampla defesa e o contraditório como garantias fundamentais e, por assim dizer, irrenunciáveis perante as situações concretas que envolvam lides ou acusações. Nestes casos, é imperativo, antes da decisão administrativa final, oferecer ampla oportunidade ao administrado para contradizer as imputações que the são feitas, utilizando amplamente os meios permitidos (e reconhecidos pelo direito) para se desfraldar os fatos. Trata-se de um comando de natureza essencialmente adjetiva, o qual, uma vez inobservado, portará um vício de legalidade.

Sintetizando: em momento algum, o legislador constituinte asseverou ser a condição necessária do processo administrativo a existência de litigantes ou acusados em geral. Apenas disse que, nos processos envolvendo conflito de interesses, requer-se a observância do contraditório e da ampla defesa.

A bem da verdade, soa-nos como se os respeitáveis filiados à idéia de processo administrativo atrelada à lide ainda o visualizassem com o ranço do processo administrativo disciplinar. Mas - repisemos o ponto - insistir em tal orientação hermenêutica somente revela uma visão reducionista do processo perante nosso ordenamento jurídico vigente.

A análise do fenômeno processual tem de ser realizada de forma fria e descontaminada das imagens do passado, ${ }^{62}$ sobretudo na esfera administrativa, possibilitando ao processso administrativo ser o meio adequado de atuação estatal, independentemente das consequiências do ato jurídico final: se ampliativo ou restritivo de direito. ${ }^{63}$

O rumo tomado pelas nossas anotações possibilita ao interlocutor perceber que cremos firmemente na distinção semântica entre os signos processo e procedimento

62 "Pour analyser correctement nos institutions, et donner une formulation abstraite scientifiquement valable, il faut commencer par oublier les idéologies, éviter de s'identifier aux créateurs du droit, et considerer les institutions et les idées comme les objets d'une analyse qui nous seraient aussi étrangers que les institutions des Incas" (Francis Paul-Bénoit, Le Droit Administratif Français, p. 39).

63 Cf. Celso Antônio Bandeira de Mello, Curso de Direito Administrativo, p. 429. 
administrativo, haja vista a diversidade de conteúdos perante a realidade edificada pelo direito positivo.

O processo administrativo, ${ }^{64}$ à luz da Carta Maior de 1988, refere-se às atividades desenvolvidas pelo Estado, no exercício regular da função administrativa. Ademais, ressalte-se que o processo protagoniza um relevante papel na organização democrática nacional, pois, ao esmerar uma relação jurídica interpessoal para aplicação/criação do direito, consubstancia-se em verdadeiro instrumento de exercício de poder, capaz de superar atuações autoritárias ou arbitrárias. ${ }^{65}$

Já o procedimento administrativo reflete o encadeamento lógico-material de atos e fatos jurídicos, por onde se desenvolve a relação processual, do momento de sua deflagração até a conclusão. Ou seja, o aspecto procedimental diz respeito à forma como o processo se realiza, é a exteriorização dos seus atos e fatos". ${ }^{66.67}$

\section{As fases do procedimento administrativo}

Oswaldo Aranha Bandeira de Mello ${ }^{68}$ adverte que os atos administrativos, "na maioria das vezes, se apresentam como integrados em um procedimento administrativo". Ainda segundo a lição do citado autor, observa-se uma pluralidade de atos jurídicos autônomos que, "embora não tenham a mesma natureza e não sejam contemporâneos, são ordenados em processo logicamente estabelecido. Cada um é distinto do outro e cada um constitui parte do todo, presos por um liame de interdependência".

De fato, consideramos inolvidável a regra geral de que o processo de formação dos provimentos administrativos ${ }^{69}$ pressupõe uma série de atos autônomos, alojados em fases interlocutórias voltadas à estruturação da decisão final. Mas, não nos parece exato fingir a inexistência das excepcionais hipóteses, onde o Poder Público lança mão de certas manifestações jurídicas para aplicação dos comandos legislados de forma instantânea e expressada em um único ato, sem concorrência da participação do interessado, ou seja, situações são bastante extraordinárias, mas suscetíveis de verificação empírica.

64 O mesmo se diga dos processos legislativo e jurisdicional, no desempenho das funções estatais pertinentes.

65 Cf. Carmen Lúcia Antunes Rocha, Princípios.... op. cit., pp. 191-2.

66 Cássio Scarpinella Bueno, op. cit., p. 192.

67 Cândido Dinamarco pondera: “A lei traça o modelo dos atos do processo, sua sequência, seu encadeamento, disciplinando com isso o exercício do poder e oferecendo a todos a garantia de que cada procedimento a ser realizado em concreto terá conformidade com o modelo preestabelecido: desvios ou omissōes quanto a esse plano de trabalho e participação constituem violações à garantia constitucional do devido processo legal" ( $A$ instrumentalidade do Processo, 1986, pp. 111-2).

68 Principios..., op. cit., p. 535.

69 "Il procedimento si inquadra nel più ampio fenomeno della formazione progressiva della fattispecie" (Pietro Virga, Diritto Amministrativo, Vol. 2, p. 58). 
Essa reduzida gama de prescrições estatais não passou desapercebida a Aldo Sandulli, ${ }^{70}$ tendo este autor oportunamente frisado: " non mancano infatti casi in cui um effetto giuridico viene (legittimamente) realizzato in virtù di um atto amministrativo individuale venuto in essere non sulla base di um procedimento (casi in cui um'autorità individuale uno actu prende l'iniziativa e provvede: per es, ordinanze e altri provvedimenti d'urgenza)". ${ }^{71}$

Não obstante a mencionada exceção, trataremos a seguir das fases logicamente estruturadas para efetivação do processo de criação/aplicação do direito positivado na esfera administrativa. ${ }^{72}$

Julgamos que as etapas do procedimento administrativo ${ }^{73}$ podem ser divididas em necessárias e eventuais. As necessárias são: (i) a deflagração; (ii) a instrução; (iii) a decisão e (iv) a exteriorização. Já as eventuais, nem sempre presentes. podem ser: (i) a integrativa e (ii) a recursiva.

$A b$ initio, dispensaremos atenção às fases aqui rotuladas por necessárias.

$\mathrm{Na}$ deflagração, há a instauração da relação processual, pondo em movimento o iter procedimental. A propulsão pode partir tanto do interessado como da própria Administração Pública (ex officio). À guisa de exemplo, podemos citar a publicação do instrumento convocatório em um processo de licitação.

A instrução é a etapa onde são consagrados todos os "atos e fatos administrativos que levem à decisão". ${ }^{74} \mathrm{O}$ momento instrutório é muito importante, sobretudo

70 Procedimento Amministrativo, op. cit., p. 1023.

71 Consultar também: Pietro Virga, Il Provvedimento Amministrativo, p. 244.

72 “Terminologicamente é muito comum a confusão entre processo, procedimento e autos. Mas, como se disse, procedimento é mero aspecto formal do processo, não se confundindo conceitualmente com este; autos por sua vez, são a materialidade dos documentos em que se corporificam os atos do procedimento. Assim, não se deve falar, por exemplo, em fases do processo, mas do procedimento; nem em 'consultar o processo' mas os autos" (Antonio Carlos de Araújo Cintra, Ada Pellegrini Grinover e Cândido Dinamarco, Teoria Geral..., op. cit., p. 276).

73 As fases do procedimento administrativo são igualmente tratadas de forma diversa pelos mais respeitados juspublicistas nacionais ou estrangeiros. Lúcia Valle Figueiredo (Curso de Direito..., op. cit., pp. 424-7) diz que as fases do procedimento são: i) a deflagatória ou propulsiva (instauração); ii) instrutória (atos e fatos administrativos que levam à decisão) e iii) decisória (que poderá ser simples ou colegiada). A ilustre jurista também relaciona a fase integrativa ou de integração. mas salienta que tal etapa não é obrigatória a todos os procedimentos, ocorrendo somente quando houver expressa exigência. Elio Fazzallari (op. cit., p. 826) afirma que qualquer provimento (declaratórios, constitutivos, concessivos, autorizatórios ou ablatórios) se expressa por três fases, a saber: i) preparatória do provimento, ii) constitutiva e iii) integrativa da eficácia. No mesmo sentido é Aldo Sandulli (op. cit., p. 1022 e ss.). Já Celso Antônio Bandeira de Mello (In: Curso..., op. cit., p. 430-1) defende cinco fases, a saber: i) iniciativa; ii) instrutória; iii) dispositiva; iv) controladora e v) comunicação. Por fim, Pietro Virga (Diritto..., op. cit. Vol. 2, p. 71 e ss.) assume a existência de três fases fundamentais: i) preparatória (compreendendo as etapas de iniciativa e instrução); ii) dispositiva (que põe o provimento final) e iii) integrativa de eficácia (subdividida em fase de controle e fase de comunicação).

74 Lúcia Valle Figueiredo, Curso..., op. cit., p. 425. 
nos atos ablatórios, pois será a oportunidade de o interessado, através do contraditório, trazer aos autos os instrumentos técnicos necessários à sua ampla defesa. ${ }^{75}$

Encerrada a instrução, o Poder Público é levado a tomar a decisão, manifestando o desfecho do processo. O período decisório induz, em regra, o fim da relação adjetiva, projetando o surgimento do provimento administrativo que instituirá a relação jurídica de direito material intersubjetiva entre o ente estatal e o administrado(s), permeada por um dos modais deônticos: permitido, obrigatório ou proibido. ${ }^{76}$

Com a decisão elaborada pelo agente competente, é preciso o seu conteúdo ser exteriorizado ao(s) interessado(s) por um dos meios reconhecidos ou previstos pelo direito, até para ser viável a apresentação de recursos. Sobre este aspecto, Renato Alessi $^{77}$ destaca que as ações da Administração Pública, em razão da natureza de ente abstrato, diferenciam-se das dos particulares. Assim, segundo o citado autor, as manifestações do Estado somente obtêm consistência apreciável e relevância jurídica quando exteriorizadas. ${ }^{78}$

O mais relevante a se perquirir, nesta etapa, é a determinação do exato instante da exteriorização da prescrição administrativa perante a ordem jurídica. Pensamos que somente há ingresso, no sistema jurídico, no momento da disponibilização da relação interpessoal formulada por um dos meios de comunicação reconhecíveis pelo direito, em seu amplo sentido, exempli gratia: publicação na imprensa oficial, a intimação, afixação em local apropriado na repartição, entre outros.

Quanto às fases que ora apelidamos de eventuais, conforme vimos, estas se apresentam somente em certos casos especiais.

A fase integrativa é o verdadeiro exemplo de ato composto, ${ }^{79}$ pois somente com o advento do ato integrador será possível o desencadeamento dos efeitos do ato jurídico. Pietro Virga ${ }^{80}$ a rotula de "controladora", posto que o ato já se encontra elaborado e dependendo apenas da apreciação da autoridade competente para examinar sua observância formal e substancial. ${ }^{81}$ A necessária observância a tal etapa

75 Lúcia Valle Figueiredo (idem, p. 415) esclarece: “A verdade material é princípio específico do processo administrativo, como também o é do processo penal (princípio inquisitivo). A busca da verdade material é oposta ao princípio dispositivo, peculiar ao processo civil."

76 Cf. Lourival Vilanova, As Estruturas.... op. cit. p. 69 e ss.

77 Sistema Instituzionale, op. cit., p. 267.

78 No caso do procedimento para emissão do ato interrompido "l'acte n'existe pas encore et l'administration, changeant d'opinion au sujet de son opportunité ou de son legalité, arrête la procédure de son émission au moment où l'acte n'est qu'un agissement intérieur du service public. Citons um exemple: l'organe compétent donne l'ordre de ne pas publier un acte déjà émis et qui, d'aprés la loi, doit être publié au Journal Officiel' (Michel Stassinopoulos, Traité des Actes Administratifs, p. 243).

79 Cf. Elio Fazzalari, Procedimento..., op. cit., p 824.

80 Diritto..., op. cit., pp. 81-2.

81 A fase integrativa "não é necessária obrigatoriamente nos procedimentos nominados ou inominados. Dependerá de haver expressamente a exigência" (Lúcia Valle Figueiredo, Curso..., op. cit., p. 427). 
é típica no processo licitatório, onde a homologação do resultado do certame se faz obrigatório.

Por fim, temos a fase recursiva, que pode ser extraída do dispositivo constitucional enunciado no inciso LV, do art. $5^{\circ}$, da Lei Maior, uma vez que se assegura a "ampla defesa, com os meios e recursos a ela inerentes".

Note-se que, apesar da Carta de 1988 não fazer referência expressa ao princípio do "duplo grau de jurisdição", este é um corolário do sistema processualístico nacional privilegiador da dupla apreciação. ${ }^{82}$

Importante destacar que, com a apresentação do recurso administrativo por parte do interessado-recorrente, não se instaura um novo processo. Ao contrário, a fase recursiva é pertinente ao processo de criação/aplicação do direito, uma vez que a decisão do agente hierarquicamente inferior é apreciada pela autoridade superior na mesma base processual (ainda que o recorrente junte novos documentos). Com isto, apesar do chamado duplo grau de jurisdição na esfera administrativa, não há instauração de outra relação processual.

Em uma palavra: a fase recursiva não esmera novel relação jurídica adjetiva para atacar a decisão administrativa de primeiro grau, ao reverso, trata-se de encadeamento legalmente previsto e disponível ao interessado para instrumentalização da ampla defesa dos seus interesses privados. ${ }^{83}$

\section{Conclusões}

As anotações derradeiras são uma breve síntese de tudo o que fora exposto. Logo, podemos modestamente resumir o estudo:

(i) A expressão devido processo legal, originária do direito anglo-saxão, foi introduzida no ordenamento constitucional brasileiro com o advento da Constituição Federal de 1988.

(ii) $\mathrm{O}$ fenômeno escalonado de criação/aplicação do direito positivo perante as funções jurisdicional, administrativa e legislativa reveste-se de uma relação jurídica processual.

(iii) Os pontos comuns da relação processual e o exercício das funções públicas perante o Estado Democrático de Direito são: (iii.1) o processo diz respeito à positivação escalonada do direito e (iii.2) a necessária participação dos interessados da elaboração da decisão final.

82 Chiovenda (apud Vicente Greco Filho, Direito Processual..., op. cit., p. 51) reconhece no duplo grau de jurisdição uma garantia para o cidadão em três aspectos, tais sejam: “à medida que um julgamento reiterado torna, já por si, possível a correção dos erros; porque dois julgamentos são confiados a juízes diversos que apreciarão independentemente a matéria; e uma vez que o segundo juiz se apresenta como mais autorizado que o primeiro".

83 Pietro Virga (Diritto..., op. cit., p. 72) relaciona o recurso como fase de iniciativa do procedimento de segundo grau. Ao que parece, o autor refere-se à instauração de novo procedimento, onde o interessado requer um reexame de legitimidade ou de mérito do ato lesivo de direito ou de interesse legítimo. 
(iv) Não há no nosso ordenamento jurídico a ligação necessária da expressão processo administrativo como uma relação que necessariamente vislumbre-se a lide ou conflito de interesses.

(v) Todos os entes políticos da federação brasileira gozam de autonomia, que significa auto-governo, auto-organização ou, ainda, auto-regulação intestina. Desta forma, a União, os Estados, os Municípios e o Distrito Federal gozam de competência para legislar sobre o processo e o procedimento administrativo no âmbito das suas respectivas esferas político-administrativas.

(vi) Processo administrativo refere-se às atividades desenvolvidas pelo Estado, no exercício regular da função administrativa, esmerando uma relação jurídica interpessoal para aplicação/criação do direito.

(vii) Procedimento administrativo é o encadeamento lógico-material de atos e fatos jurídicos, por onde se desenvolve a relação processual, do momento de sua deflagração até a conclusão.

(viii) Julgamos que as etapas do procedimento administrativo podem ser relacionadas em necessárias e eventuais. As necessárias são: deflagração: instrução; decisão e exteriorização. Por sua vez, as eventuais, que nem sempre se fazem presentes, podem ser: integrativa e recursiva.

\section{Bibliografia}

ALESSI, Renato. Sistema Instituzionale del Diritto Amministrativo. Milão: Guiffrè, 1960.

ARAÚJO CINTRA, Antonio Carlos; GRINOVER, Ada Pellegrini e DINAMARCO,

Cândido R.. Teoria Geral do Processo. São Paulo: Malheiros, 1994.

ATALIBA, Geraldo. Normas Gerais de Direito Financeiro. Revista de Direito Público, $\mathrm{n}^{\circ} 10$.

BANDEIRA DE MELLO, Celso Antônio. Curso de Direito Administrativo. $12^{\mathrm{a}}$ ed. São Paulo: Malheiros, 2000.

BANDEIRA DE MELlO, Oswaldo Aranha. Princípios Gerais de Direito Administrativo. Vol. I. Rio de Janeiro: Forense, 1978.

. A Teoria das Constituições Rígidas. $2^{\mathrm{a}}$ ed. São Paulo: José Bushatsky, 1980.

BARCELAR FILHO, Romeu Felipe. Princípios Constitucionais do Processo Administrativo Disciplinar. São Paulo: Max Limonad, 1998.

BÉNOIT, Francis Paul. Le Droit Administratif Français. Paris: Dalloz, 1968.

BORGES, José Souto Maior. Ciência Feliz. São Paulo: Max Limonad, 2000.

COLE, Charles. O Devido Processo Legal na Cultura dos Estados Unidos: Passado, Presente e Futuro. Revista da AJUFE, $\mathrm{n}^{\circ}$ 56, 1997.

DALLARI, Dalmo de Abreu. Elementos de Teoria Geral do Estado. $19^{\text {a }}$ ed. São Paulo: Saraiva, 1995.

ENTERRÍA, Eduardo Garcia de e FERNÁNDEZ, Tomás-Ramón. Curso de Derecho Administrativo. Vol. II. Madri: Civitas, 1988. 
FAZZALARI, Elio. "Procedimento (Teoria Generale)". Enciclopedia del Diritto. Milano: Guiffré, 1986.

FIGUEIREDO, Lúcia Valle. Curso de Direito Administrativo. $4^{a}$ ed. São Paulo: Malheiros, 2000.

"Devido Processo Legal e Fundamentação das Decisões". Revista de Direito Tributário, vol. 63. São Paulo: Malheiros.

GORDILLO, Agustín. Tratado de Derecho Administrativo. Tomos I e II. Buenos Aires: Fundación de Derecho Administrativo, 1998.

GRECO FILHO, Vicente. Direito Processual Brasileiro. Vol. 1. São Paulo: Saraiva, 2000.

HÄBERLE, Peter. Hermenêutica Constitucional (trad. Guilmar Ferreira Mendes). Porto Alegre: Sérgio Fabris Editor, 1997.

HARGER, Marcelo. Principios Constitucionais de Processo Administrativo. Rio de Janeiro: Forense, 2001.

KELSEN, Hans. Teoria Geral do Estado e do Direito. São Paulo: Martins Fontes, 1998.

MEDAUAR, Odete. A Processualidade no Direito Administrativo. São Paulo: Revista dos Tribunais, 1993.

MEIRELLES, Hely Lopes. Direito Administrativo Brasileiro. São Paulo: Malheiros, 1994.

MEIRELLES TEIXEIRA, J. H. Curso de Direito Constitucional (org. Maria Garcia). Rio de Janeiro: Forense Universitária, 1991.

MOREIRA, Egon Bockmann. Processo Administrativo. São Paulo: Malheiros, 2000.

NEVES, Marcelo. Teoria da Inconstitucionalidade das Leis. São Paulo: Saraiva, 1988.

PIETRO, Maria Sylvia Zanella di. Direito Administrativo. 13ª ed. São Paulo: Atlas, 2001.

PINTO FERREIRA. Princípios Gerais do Direito Constitucional Moderno. Tomo II. Rio de Janeiro: José Konfino, 1955.

ROCHA, Cármen Lúcia Antunes. "Princípios Constitucionais da Administração Pública". Revista de Direito Administrativo, n²09, Rio de Janeiro: Renovar, 1997.

SALMON, Wesley. Lógica. (tradução de Álvaro Cabral). $3^{\mathrm{a}}$ ed. Rio de Janeiro: Prentice Hall do Brasil, 1993.

SAMPAIO DÓRIA, Antônio Roberto. Direito Constitucional Tributário e Due Process of Law. $2^{\mathrm{a}}$ ed. Rio de Janeiro: Forense, 1986.

SAN TIAGO DANTAS, F. C. de. Igualdade Perante a Lei e Due Process of Law. Rio de Janeiro: Revista Forense, 1953.

SCARPINELLA BUENO, Cássio. Recursos nas Leis de Processo Administrativo (orgs. Carlos Ari Sundfeld e Guillermo Andrés Muñoz). São Paulo: Malheiros, 2000.

SILVA, José Afonso da. Curso de Direito Constitucional. São Paulo: Malheiros, 1993.

SIQUEIRA CASTRO, Carlos Roberto de. O Devido Processo Legal e a Razoabilidade das Leis na Nova Constituição do Brasil. Rio de Janeiro: Forense, 1989. 
STASSINOPOULOS, Michel. Traité des Actes Administratifs. Paris: Librarie Générale de Droit et de Jurisprudence, 1973.

SUNDFELD, Carlos Ari. Fundamentos de Direito Público. São Paulo: Revista dos Tribunais, 1990.

"A Importância do Procedimento Administrativo". Revista de Direito Público, $\mathrm{n}^{\circ}$ 84, ano 1987.

VILANOVA, Lourival. As Estruturas Lógicas e o Sistema do Direito Positivo. São Paulo: Max Limonad, 1997.

VIRGA, Pietro. Diritto Amministrativo. Vol. 2. Milão: Guiffrè, 1997.

WEBER, Albrecht. El Procedimiento Administrativo en el Derecho Comunitario (coord. Janvier Barnes Vazquez). $1^{\text {a }}$ ed. Madri: Consejeria de la Presidencia de la Junta de Andalucia e Civitas, 1993. 